\title{
The association between smoking or passive smoking and cardiovascular diseases using a Bayesian hierarchical model: based on the 2008-2013 Korea Community Health Survey
}

\author{
Whanhee Lee, Sung-Hee Hwang, Hayoung Choi, Ho Kim \\ Graduate School of Public Health, Seoul National University, Seoul, Korea
}

\begin{abstract}
OBJECTIVES: Smoking and passive smoking have been extensively reported as risk factors of cardiovascular morbidity and mortality. Despite the biological mechanisms underlying the impact of hazardous chemical substances contained in tobacco in cardiovascular diseases (CVD), studies investigating the association between smoking and passive smoking with morbidity are at an inchoate stage in Korea. Therefore, this study aimed to estimate the risks of smoking and passive smoking on cardiovascular morbidity at the national and regional levels.
\end{abstract}

METHODS: This study calculated sex-standardized and age-standardized prevalence of CVD and smoking indices in 253 community health centers (si/gun/gu) in Korea using the 2008-2013 Korea Community Health Survey data. Furthermore, a Bayesian hierarchical model was used to estimate the association of smoking and passive smoking with the prevalence of CVD from the national and regional community health centers.

RESULTS: At the national level, smoking was significantly associated with stroke (relative risk [RR], 1.060) and hypertension $(\mathrm{RR}, 1.016)$ prevalence, whilst passive smoking at home and work were also significantly associated with prevalence of stroke (RR, 1.037/1.013), angina (RR, 1.016/1.006), and hypertension (RR, 1.010/1.004). Furthermore, the effects of smoking and passive smoking were greater in urban-industrial areas than in rural areas.

CONCLUSIONS: The findings of this study would provide grounds for national policies that limit smoking and passive smoking, as well as regionally serve as the basis for region-specific healthcare policies in populations with high CVD vulnerability.

KEY WORDS: Smoking, Passive smoking, Cardiovascular diseases, Korea Community Health Survey, Korea

\section{INTRODUCTION}

Smoking and passive smoking have extensively been documented as risk factors of morbidity and mortality by a number of dis-

\section{Correspondence: Ho Kim}

Graduated School of Public Health, Seoul National University,

1 Gwanak-ro, Gwanak-gu, Seoul 08826, Korea

E-mail: hokim@snu.ac.kr

Received: Jan 2, 2017 / Accepted: Jan 17, 2017 / Published: Jun 22, 2017

This article is available from: http://e-epih.org/

(C) This is an open-access article distributed under the terms of the Creative Commons Attribution License (http://creativecommons.org/licenses/by/4.0/), which permits unrestricted use, distribution, and reproduction in any medium, provided the original work is properly cited.

(C) 2017, Korean Society of Epidemiology eases [1-4]. Among more than 4,000 types of chemical substances contained in a cigarette, polycyclic aromatic hydrocarbons and oxidizing gases cause cardiac toxicity [1], having adverse effects on various cardiovascular diseases (CVD), including coronary artery disease, ischemic stroke, non-traumatic subarachnoid hemorrhage $[5,6]$.

The World Health Organization reported that CVD-related death (1.69 million) is the leading cause of smoking-related death. In a study on 360 thousand US men, smoking has been identified as a key risk factor for lung cancer, chronic heart disease, and stroke [3]. In addition, a Norwegian study revealed that smokers are 2.74 times more likely to have a stroke and 6.74 times more likely to die from it than are non-smokers [4]. Similar to the effects of smoking, passive smoking has also been reported to be the cause of respiratory and CVD, various cancers, and premature deaths in non- 
smoking adults [7]. Other studies have suggested that secondhand smoking in non-smokers increases their risk of developing a heart disease by 25 to $30 \%$ [8-10].

In South Korea (hereafter Korea), several studies have reported that smoking increases the risk of CVD-related death in adults [11-13]. As of 2012, the number of smoking-related deaths was 4,148 for stroke and 3,858 for ischemic heart disease, which are ranked the second and third highest causes of death by an illness respectively [14]. Furthermore, it also has been reported that $26.7 \%$ of all CVD-related deaths in men and women adults in Korea are caused by smoking [13]. Although adult smoking rate in Korea has consistently been on a decline since 1998 [15], past smoking history may have an impact on death [11]. Moreover, medical expenses and patient population related to hypertension, heart disease, and cerebrovascular disease are continuously on the rise [16], suggesting that smoking is a health hazard in terms of CVD and mortality requiring much attention.

As shown here, though there have been much research investigating the association between smoking and death by CVD in Korea, studies on smoking and morbidity is relatively lacking. Hence, this study aimed at quantitatively analyzing the association between smoking and the prevalence of various CVD (i.e., hypertension, stroke, myocardial infarction, angina), and to evaluate the relative risk (RR) of smoking on the prevalence of CVD using data from a large-scale cross-sectional study with more than 1.5 million participants. We also examined the effects of passive smoking on the prevalence of CVD.

\section{MATERIALS AND METHODS}

\section{Data}

Data from the 2008-2013 Korea Community Health Survey (KCHS) involving 253 community health centers were used for this study [17]. The KCHS was conducted by the Korea Centers for Disease Control and Prevention, and data collected from adults aged 19 years or older via interviews. The sample was extracted from an average of 900 adults per community (si/gun/gu) based on the type of housing within each dong/eup/myeon. The primary sample region was obtained using a probability proportional to size systematic sampling, after which the secondary sample families were selected [18]. A total of 1,567,930 people were included in the KCHS data used in this study (2008: 200,800; 2009: 220,258; 2010: 230,712; 2011: 229,229; 2012: 229,226; 2013: 228,781), and the participants were randomly extracted every year. Using this data, we calculated the prevalence of 4 CVD (hypertension in adults $\geq 30$ years, stroke in adults $\geq 50$ years, myocardial infarction in adults $\geq 40$ years, angina in adults $\geq 40$ years), smokingrelated regional parameters (current smoking rate, passive smoking rate at home, and passive smoking rate at work), body mass index (BMI), and monthly drinking rate by community (si/gun/gu), after reflecting gender/age distributions based on the year of study. The prevalence of CVD was measured, based on a self-reported response regarding a physician's diagnosis, whilst BMI and monthly drinking rates were also measured with self-reported data.

\section{Statistical analysis}

A generalized linear mixed model (GLMM) was used to analyze the association among regional and national smoking indices and prevalence of CVD that were repeatedly measured from 20082013. The prevalence of 4 CVD (hypertension in adults $\geq 30$ years, stroke in adults $\geq 50$ years, myocardial infarction in adults $\geq 40$ years, and angina in adults $\geq 40$ years) was set as the response variables. A Shapiro-Wilk test revealed that the prevalence of all 4 diseases did not follow a normal distribution, but instead showed a gamma distribution. Hence, a GLMM that assumes gamma distribution for the response variables was used. A log function was used as the link function. Mean BMI and monthly drinking rate per community (si/gun/gu) for 2008-2013, were set as the respective confounding variables and covariate, and a linear adjustment was made for annual effects to consider the effects of time. Smoking indices (current smoking rate, passive smoking rate at home, passive smoking rate at work) were used as the response variables, and we predicted associations with response variables with equal confounding variables and covariates.

Furthermore, a Bayesian hierarchical model was used with a GLMM to measure the effects of smoking indices of each community (si/gun/gu) and adjust for the correlations according to distance. The associations between community (si/gun/gu)-spe-

Table 1. Descriptive statistics for regional prevalence of CVD and confounders

\begin{tabular}{|c|c|c|c|c|c|c|c|c|}
\hline & Diseases & Period & Mean (SD) & Min & $25 \%$ & Median & $75 \%$ & Max \\
\hline \multirow[t]{4}{*}{ CVD (yr) } & Hypertension (> 30) & 2008-2013 & $18.2(2.4)$ & 10.0 & 16.5 & 18.3 & 19.9 & 25.6 \\
\hline & Stroke $(>50)$ & & $3.3(1.1)$ & 0.4 & 2.6 & 3.2 & 4.0 & 7.7 \\
\hline & Myocardial infarction $(>40)$ & & $1.4(0.6)$ & 0.1 & 1.0 & 1.4 & 1.8 & 4.6 \\
\hline & Angina (>40) & & $1.9(0.7)$ & 0.2 & 1.4 & 1.8 & 2.3 & 4.4 \\
\hline \multirow[t]{5}{*}{ Confounders (\%) } & Smoking rate & $2008-2013$ & $25.2(2.9)$ & 14.9 & 23.3 & 25.2 & 27.2 & 33.4 \\
\hline & Passive smoking (at home) rate & 2009-2011, 2013 & $11.8(4.1)$ & 2.3 & 9.1 & 11.3 & 14.1 & 37.3 \\
\hline & Passive smoking (at work) rate & 2009-2011, 2013 & $29.2(9.3)$ & 6.0 & 23.8 & 28.6 & 34.9 & 76.7 \\
\hline & Drinking rate per month & $2008-2013$ & $56.5(5.4)$ & 32.9 & 53.2 & 57.1 & 60.4 & 68.8 \\
\hline & Body mass index & $2008-2013$ & $23.0(0.7)$ & 22.2 & 22.8 & 23.0 & 23.1 & 34.5 \\
\hline
\end{tabular}

CVD, cardiovascular disease; SD, standard deviation; Min, minimum; Max, maximum. 
Lee Wet al. : Smoking or passive smoking-related CVD relationship

Table 2. Higher and lower 5 community health centers (si/gun/gu) of cardiovascular disease prevalence

\begin{tabular}{|c|c|c|c|c|c|}
\hline & & Si/do & Si/gun/gu & Mean & Standard deviation \\
\hline \multicolumn{6}{|l|}{ Prevalence (\%) } \\
\hline \multirow[t]{10}{*}{ Hypertension (>30 yr) } & \multirow{5}{*}{$\begin{array}{c}\text { Higher } \\
5 \text { communities }\end{array}$} & Gangwon & Sokcho & 22.35 & 1.74 \\
\hline & & Incheon & Dong & 22.10 & 2.21 \\
\hline & & Gangwon & Goseong & 21.98 & 0.63 \\
\hline & & Gangwon & Samcheok & 21.88 & 1.05 \\
\hline & & Gangwon & Yeongwol & 21.72 & 2.13 \\
\hline & \multirow{5}{*}{$\begin{array}{l}\text { Lower } \\
5 \text { communities }\end{array}$} & Gyeongnam & Hapcheon & 14.03 & 1.50 \\
\hline & & Jeonbuk & Imsil & 14.05 & 2.85 \\
\hline & & Gyeongbuk & Seongju & 14.48 & 1.78 \\
\hline & & Jeonnam & Naju & 14.50 & 1.13 \\
\hline & & Gyeongnam & Sancheong & 14.72 & 1.15 \\
\hline \multirow[t]{10}{*}{ Stroke $(>50 \mathrm{yr})$} & \multirow{5}{*}{$\begin{array}{c}\text { Higher } \\
5 \text { communities }\end{array}$} & Gyeongbuk & Gumi-Gumi & 5.33 & 1.71 \\
\hline & & Chungnam & Asan & 4.88 & 1.36 \\
\hline & & Gangwon & Yeongwol & 4.75 & 1.79 \\
\hline & & Gyeongbuk & Gimcheon & 4.72 & 0.81 \\
\hline & & Gyeongbuk & Andong & 4.68 & 0.41 \\
\hline & \multirow{5}{*}{$\begin{array}{c}\text { Lower } \\
5 \text { community health centers }\end{array}$} & Busan & Suyeong & 1.87 & 0.97 \\
\hline & & Jeonnam & Jangheung & 1.93 & 0.75 \\
\hline & & Jeonnam & Yeongam & 1.97 & 0.76 \\
\hline & & Jeonnam & Wando & 2.00 & 0.58 \\
\hline & & Jeonnam & Gangjin & 2.12 & 0.38 \\
\hline \multirow{10}{*}{$\begin{array}{l}\text { Myocardial infarction } \\
(>40 \mathrm{yr})\end{array}$} & \multirow{5}{*}{$\begin{array}{c}\text { Higher } \\
5 \text { community health centers }\end{array}$} & Jeonnam & Damyang & 2.38 & 1.24 \\
\hline & & Jeju & Jeju-Jeju & 2.28 & 0.50 \\
\hline & & Gyunggi & Goyang-Ilsanseo & 2.25 & 1.18 \\
\hline & & Seoul & Nowon & 2.20 & 0.84 \\
\hline & & Seoul & Dongjak & 2.12 & 0.44 \\
\hline & \multirow{5}{*}{$\begin{array}{l}\text { Lower } \\
5 \text { community health centers }\end{array}$} & Gyeongnam & Hamyang & 0.68 & 0.27 \\
\hline & & Daegu & Dalseong & 0.72 & 0.40 \\
\hline & & Gyeongbuk & Sungju & 0.72 & 0.26 \\
\hline & & Jeonbuk & Sunchang & 0.78 & 0.12 \\
\hline & & Jeonbuk & Jangsu & 0.83 & 0.32 \\
\hline \multirow[t]{10}{*}{ Angina (> $40 \mathrm{yr}$ ) } & \multirow{5}{*}{$\begin{array}{c}\text { Higher } \\
5 \text { community health centers }\end{array}$} & Busan & Yeonje & 3.25 & 0.49 \\
\hline & & Gwangju & Nam & 2.97 & 0.69 \\
\hline & & Chungbuk & Cheonan & 2.92 & 0.80 \\
\hline & & Busan & Dong & 2.90 & 0.18 \\
\hline & & Busan & Gijang & 2.88 & 0.96 \\
\hline & \multirow{5}{*}{$\begin{array}{c}\text { Lower } \\
5 \text { community health centers }\end{array}$} & Gyeongbuk & Sungju & 0.87 & 0.12 \\
\hline & & Jeonbuk & Jinan & 1.03 & 0.36 \\
\hline & & Ulsan & Dong & 1.07 & 0.34 \\
\hline & & Jeonbuk & Wanju & 1.08 & 0.58 \\
\hline & & Chungbuk & Jecheon & 1.20 & 0.70 \\
\hline \multicolumn{6}{|l|}{ Smoking index (\%) } \\
\hline \multirow[t]{10}{*}{ Smoking rate } & \multirow{5}{*}{$\begin{array}{c}\text { Higher } \\
5 \text { community health centers }\end{array}$} & Gangwon & Taebaek & 31.62 & 1.61 \\
\hline & & Gyeonggi & Dongducheon & 29.72 & 1.77 \\
\hline & & Chungbuk & Eumseong & 29.67 & 2.80 \\
\hline & & Busan & Jung & 29.37 & 2.19 \\
\hline & & Gyeonggi & Bucheon -Ojeong & 29.35 & 1.19 \\
\hline & \multirow{5}{*}{$\begin{array}{c}\text { Lower } \\
5 \text { community health centers }\end{array}$} & Gyeonggi & Gwacheon & 17.37 & 1.68 \\
\hline & & Gyeonggi & Seongnam -Bundang & 17.50 & 2.01 \\
\hline & & Seoul & Seocho & 19.57 & 1.24 \\
\hline & & Gyeonggi & Yongin -Suji & 20.00 & 1.70 \\
\hline & & Chungnam & Gyeryong & 20.77 & 1.58 \\
\hline
\end{tabular}

(Continued to the next page) 
Table 2. Continued

\begin{tabular}{|c|c|c|c|c|c|}
\hline & & $\mathrm{Si} / \mathrm{do}$ & $\mathrm{Si} / g u n / g u$ & Mean & Standard deviation \\
\hline \multirow{10}{*}{$\begin{array}{l}\text { Passive smoking } \\
\text { (at home) rate }\end{array}$} & \multirow{5}{*}{$\begin{array}{c}\text { Higher } \\
5 \text { community health centers }\end{array}$} & Incheon & Ongjin & 24.45 & 8.65 \\
\hline & & Jeju & Dongbu & 21.80 & 3.56 \\
\hline & & Jeju & Seogwipo (west) & 19.90 & 6.24 \\
\hline & & Jeju & Jeju -Seo(west) & 19.88 & 3.74 \\
\hline & & Jeonbuk & Gimje & 19.10 & 8.13 \\
\hline & \multirow{5}{*}{$\begin{array}{l}\text { Lower } \\
5 \text { community health centers }\end{array}$} & Busan & Suyeong & 6.28 & 2.47 \\
\hline & & Gyeongnam & Yangsan & 6.28 & 0.75 \\
\hline & & Jeonnam & Gurye & 6.73 & 3.40 \\
\hline & & Gyeonggi & Gwacheon & 6.78 & 2.44 \\
\hline & & Gangwon & Wonju & 6.78 & 2.42 \\
\hline \multirow{10}{*}{$\begin{array}{l}\text { Passive smoking } \\
\text { (at work) rate }\end{array}$} & \multirow{5}{*}{$\begin{array}{c}\text { Higher } \\
5 \text { community health centers }\end{array}$} & Chungnam & Dangjin & 42.83 & 24.56 \\
\hline & & Ulsan & Nam & 41.70 & 10.22 \\
\hline & & Ulsan & Jung & 41.40 & 9.40 \\
\hline & & Ulsan & Ulju & 40.93 & 12.45 \\
\hline & & Gyeongnam & Changwon-Masan & 40.83 & 5.25 \\
\hline & \multirow{5}{*}{$\begin{array}{l}\text { Lower } \\
5 \text { community health centers }\end{array}$} & Gyeongbuk & Uiseong & 15.70 & 7.03 \\
\hline & & Jeonnam & Gurye & 15.83 & 8.81 \\
\hline & & Jeonnam & Goheung & 15.85 & 13.30 \\
\hline & & Jeonbuk & Jangsu & 17.58 & 13.55 \\
\hline & & Jeonnam & Hampyeong & 18.55 & 4.71 \\
\hline
\end{tabular}

Table 3. Relative risk of smoking/passive smoking (at home)/passive smoking (at work) by cardiovascular diseases (per 5\% smoking or passive smoking rate)

\begin{tabular}{lccc}
\hline & Smoking & Home & Exposure to passive smoking \\
\cline { 3 - 4 } & & $1.010(1.006,1.014)$ & $1.004(1.002,1.006)$ \\
\hline Hypertension $(>30 \mathrm{yr})$ & $1.016(1.004,1.029)$ & $1.037(1.023,1.051)$ & $1.013(1.007,1.019)$ \\
Stroke $(>50 \mathrm{yr})$ & $1.060(1.022,1.100)$ & $1.003(0.986,1.021)$ & $0.998(0.991,1.006)$ \\
Myocardial infarction $(>40 \mathrm{yr})$ & $1.004(0.958,1.051)$ & $1.016(1.001,1.032)$ & $1.006(1.000,1.013)$ \\
\hline Angina $(>40 \mathrm{yr})$ & $1.007(0.966,1.049)$ & & \\
\hline
\end{tabular}

Values are presented relative risk ( $95 \%$ credibility interval).

cific smoking indices and CVD were examined with random intercept and random slope, and the prior distributions of random intercept and random slope were assumed to follow a normal distribution with mean zero and an assumption that the inverse of variance follows a gamma distribution (parameter $=1,5^{\star} 10^{-5}$ ). Spatial correlation was adjusted for, with random intercept using the Besag-York-Mollie method [19], and all random intercepts and random slopes were assumed to be independent. Based on existing studies, the prior distribution of fixed effects was assumed a multivariate normal, which assumes variance to be a Gaussian Markov random field [20], and the posterior credibility interval (CI) was estimated based on the prior distribution. All analyses were performed using the $\mathrm{R}$ and $\mathrm{R}$ version 3.2.2 (https://cran.rproject.org/bin/windows/base/old/3.2.2/) for integrated nested Laplace approximation (INLA) [21]. More detailed formula and prior conditions are reported in Appendix 1.

\section{RESULTS}

Table 1 shows the descriptive statistics for the variables used in this study. Hypertension over 30 years was the most prevalent (18.2\%) throughout the 6 years of study (2008-2013), while angina over 40 years was the least prevalent (1.9\%). The distributions of prevalence varied widely across the country. The average smoking rate as an interest variable during 6 years was $25.2 \%$ (14.9 to $33.4 \%$ ), with an average passive smoking rate at home of $11.8 \%$ (2.3 to $37.3 \%)$ and an average passive smoking rate at work of $29.2 \%$ (6.0 to $76.7 \%$ ).

Table 2 shows the top and bottom 5 community health centers in terms of the prevalence of CVD and smoking indices (6-year average). Hypertension over 30 years was generally prevalent in the Gangwon province (21.72 to $22.35 \%$ ) and less prevalent in community health centers in the Gyeongsang province and Jeolla province (14.03 to $14.72 \%)$. Stroke over 50 years was generally prevalent in community health centers in the North Gyeongsang 


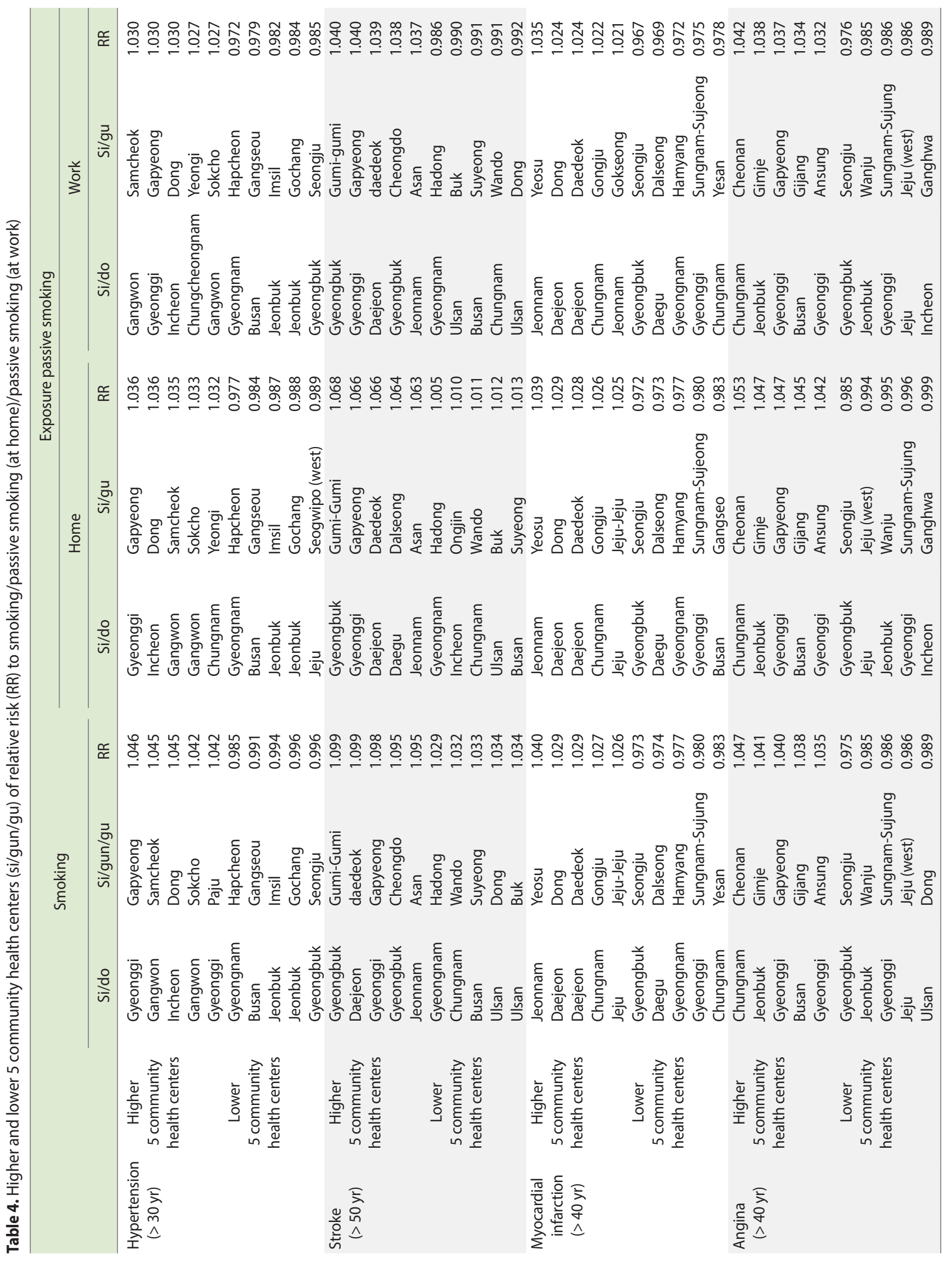


province (4.68 to 5.33\%) and less prevalent in the South Jeolla province (1.93 to $2.12 \%)$. Myocardial infarction over 40 years tended to be prevalent in community health centers in Seoul and the Gyeonggi province (2.12 to $2.25 \%$ ) and less prevalent in community health centers in North Jeolla province ( 0.78 to $0.83 \%)$. Angina over 40 years tended to be prevalent in community health centers in Busan (2.88 to 3.25\%) and less prevalent in the North Jeolla province (1.03 to $1.08 \%)$. In terms of smoking parameters, smoking rate did not vary by region. Community health centers in Jeju Island showed higher passive smoking rates at home (19.88 to $21.80 \%$ ) while community health centers in Ulsan showed higher passive smoking rates at work (40.93 to $41.70 \%$ ).

The national average $\mathrm{RR}$ of smoking indices on the prevalence of CVD is shown in Table 3, whilst the regional average (RR) for top and bottom 5 regions is shown in Table 4 . All RR shown in Tables 3 and 4 represent RR when smoking parameters increase by $5 \%$. As shown in Table 3 , smoking rate was most highly associ- ated with stroke (RR, 1.060; 95\% CI, 1.022 to 1.100 ), and it was also significantly associated with hypertension (RR, 1.016; 95\% CI, 1.004 to 1.029). Passive smoking at home was most strongly associated with a rise in the prevalence of stroke (RR, 1.037; 95\% CI, 1.023 to 1.051), and its RR for hypertension, stroke, and angina (but not myocardial infarction) was statistically significant (RR, 1.010 to 1.037). Passive smoking at work had the greatest effect on stroke (RR, 1.013; 95\% CI, 1.007 to 1.019) and also had a significant effect on hypertension (RR, 1.004; 95\% CI, 1.002 to 1.006).

Table 4 shows the top and bottom three community health centers in terms of the RRs of smoking indices, whilst Figures 1-3 are national maps showing the effects of community-specific smoking rate and passive smoking rate at home and work on the prevalence of CVD. RR of smoking rate for hypertension was high in community health centers in Gyeonggi and Gangwon provinces (RR, 1.042 to 1.046) and low in community health centers in North Jeolla and Gyeonsang provinces (RR, 0.985 to 0.996). Furthermore,

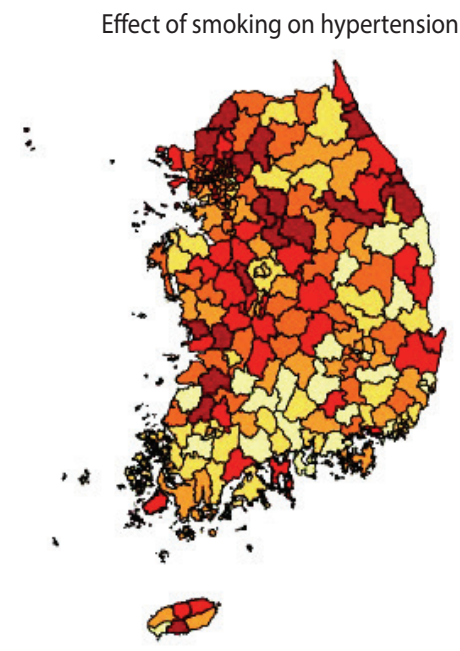

Effect of smoking on myocardial infarction

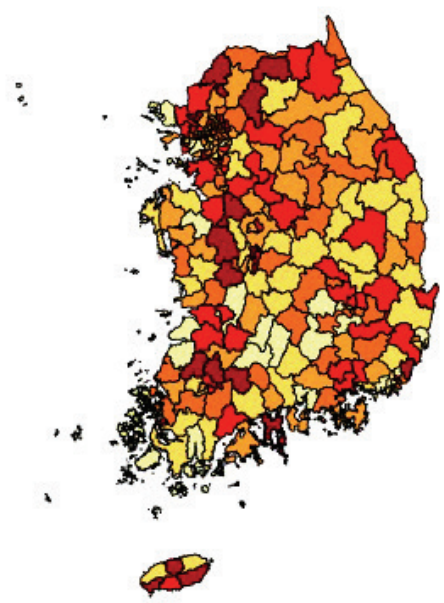

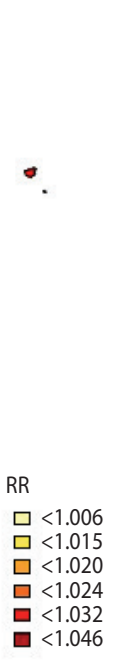
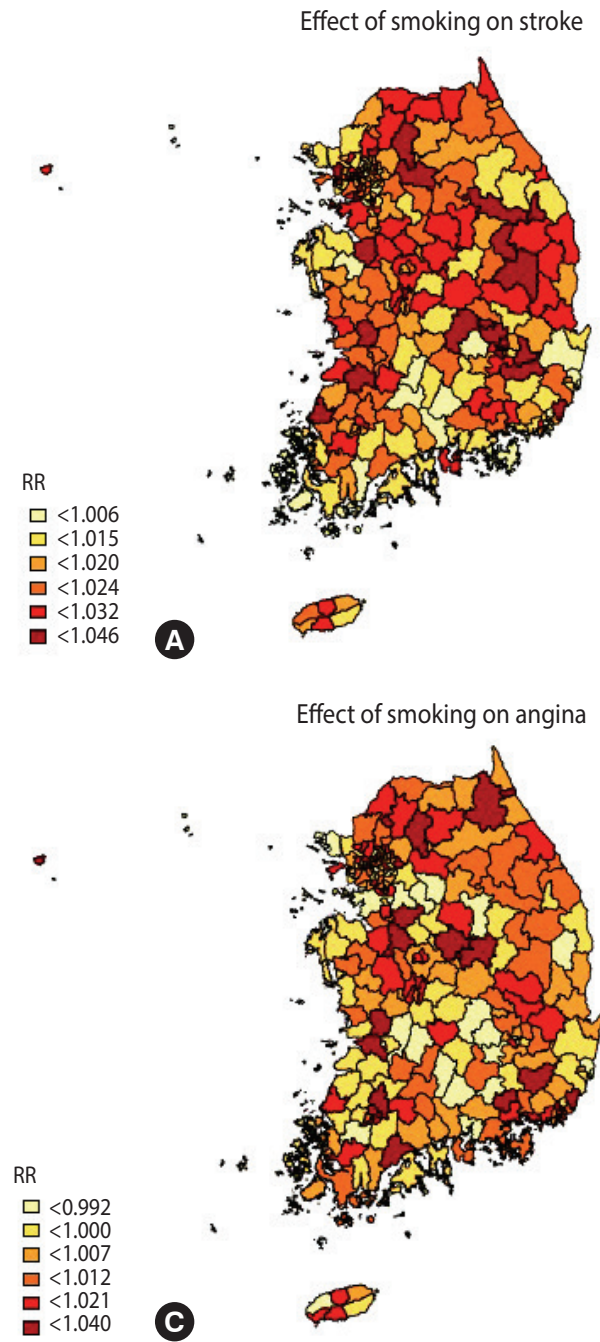

Effect of smoking on angina

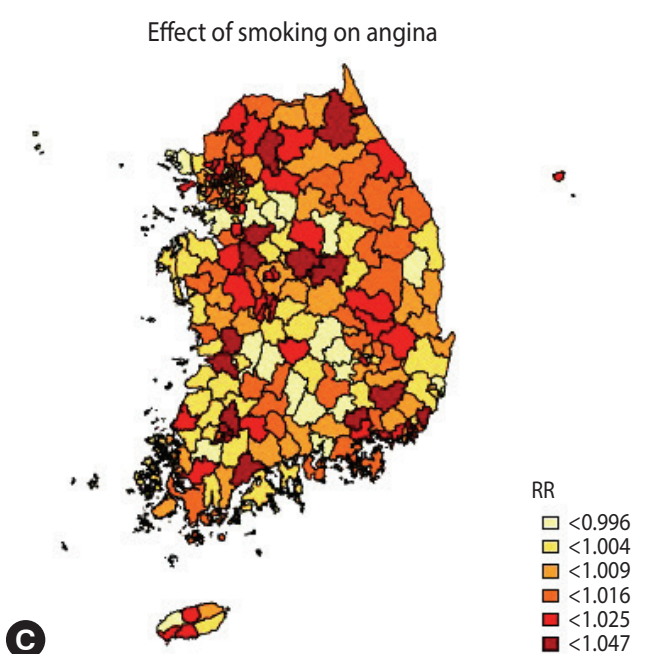

B

Figure 1. Geographical distribution of relative risks (RR). The associations between 4 cardiovascular diseases (A) hypertension over 30 years, (B) stoke over 50 years, (C) myocardial infarction over 40 years, and (D) angina over 40 years and smoking. 
Effect of passive smoking (in home) on hypertension

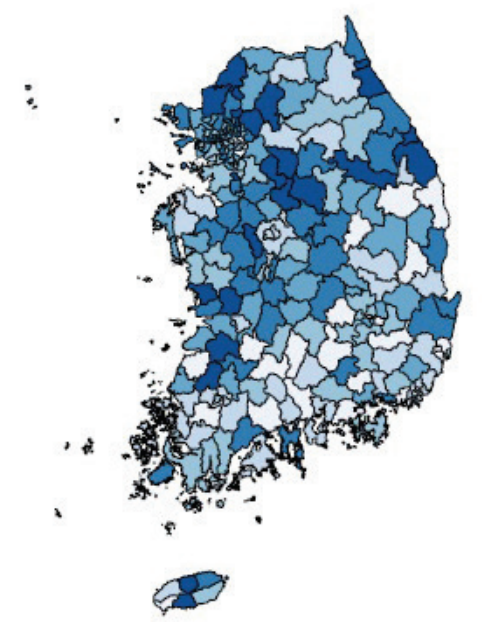

$\mathrm{RR}$

$\square<0.999$
$\square<1.007$

$\square<1.007$

$\square<1.016$

$\square<1.022$
$\square<1.036$

A
Effect of passive smoking (in home) on stroke

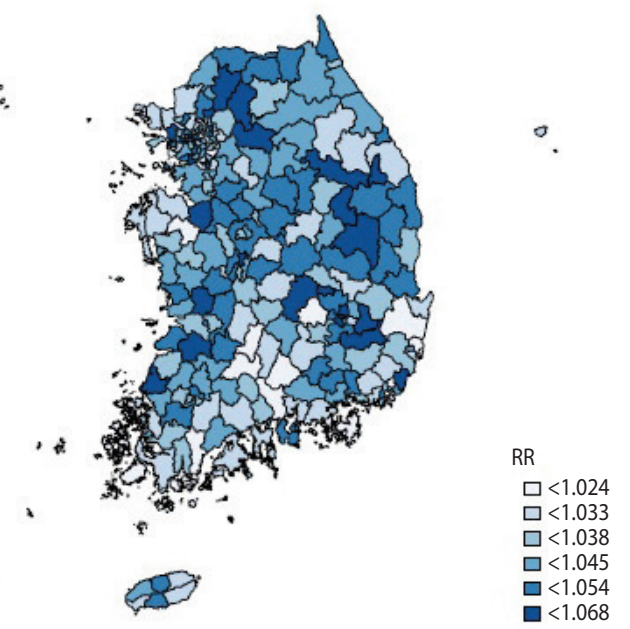

Effect of passive smoking (in home) on angina

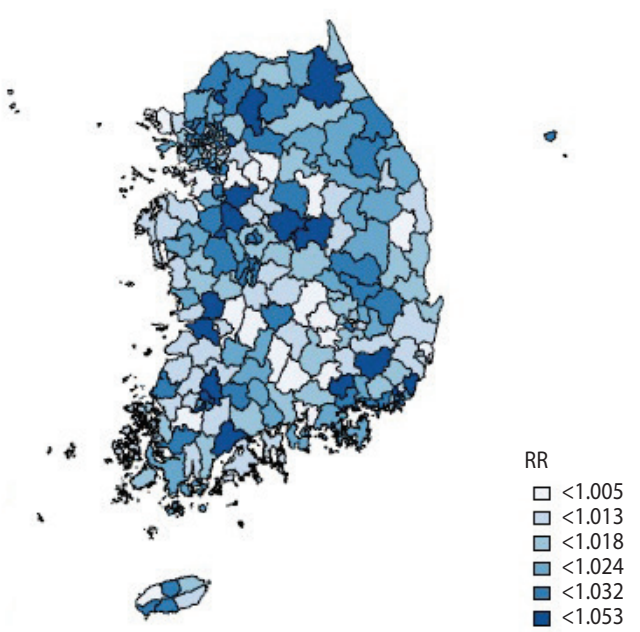

Effect of passive smoking (in home) on myocardial infarction

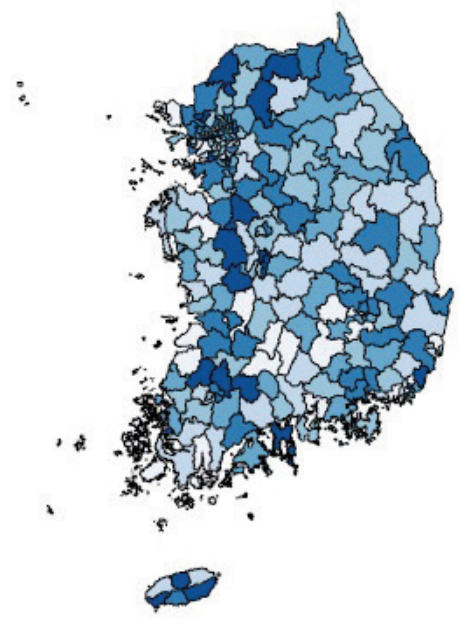

$\bullet$

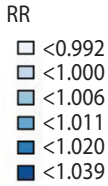

Figure 2. Geographical distribution of relative risks (RR). The associations between 4 cardiovascular diseases (A) hypertension over 30 years, (B) stoke over 50 years, (C) myocardial infarction over 40 years, and (D) angina over 40 years and passive smoking at home.

smoking was strongly associated with stroke in community health centers in North Gyeongsang province (RR, 1.095 to 1.099) but weakly associated with stroke in community health centers in $\mathrm{Bu}$ san and Ulsan (RR, 1.033 to 1.034). The RR of smoking for myocardial infarction was high in community health centers in Daejeon (RR, 1.029 to 1.029), but there were no regional differences in terms of low RR (RR, 0.973 to 0.983 ). The effects of smoking on angina was high in the Gyeonggi region (RR, 1.040 to 1.035) and low in the southern region of the Korean peninsula (North Gyeonsang, North Jeolla, and Jeju Island) (RR, 0.975 to 0.989). The distributions of RR of passive smoking at home and work were similar to those of smoking, and the community rankings were similar as well. Exposure to passive smoking at home (RR, 1.003 to 1.037 ) had greater impact on all 4 CVD than did exposure to passive smoking at work (RR, 0.998 to 1.013). In addition, the RR of all smoking indices tended to be higher in the Seoul metropolitan area (Figures 1-3).

\section{DISCUSSION}

This study analyzed the associations between regional smoking indices (smoking rate and passive smoking rate at home and work) and 4 CVD (hypertension in adults $\geq 30$ years, stroke in adults $\geq 50$ years, myocardial infarction in adults $\geq 40$ years, angina in adults $\geq 40$ years) with the KCHS data using a Bayesian hierarchical model. The results showed that smoking rate was significantly associated with stroke (RR, 1.060) and hypertension (RR, 1.016), and that passive smoking was significantly associated with stroke (RR, 1.013 to 1.037), angina (RR, 1.006 to 1.016), and hypertension (RR, 1.004 to 1.010$)$ at the national level. Furthermore, exposure to passive smoking at home (RR, 1.003 to 1.037 ) had a greater impact on CVD than did exposure to passive smoking at work 
Effect of passive smoking (in work) on hypertension

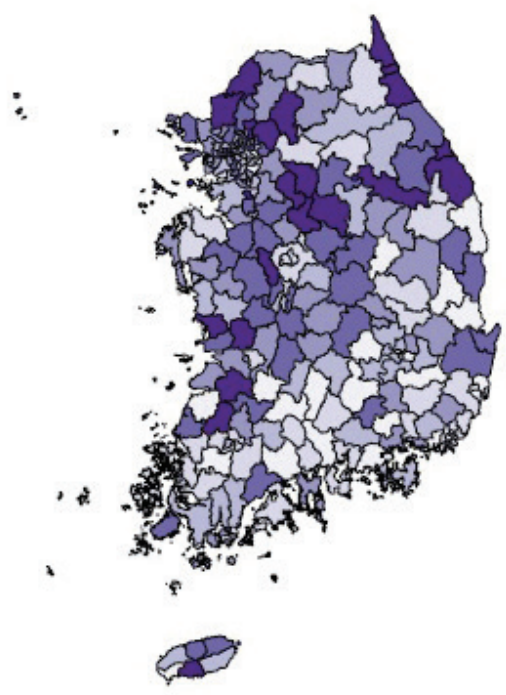

RR

Effect of passive smoking (in work) on myocardial infarction

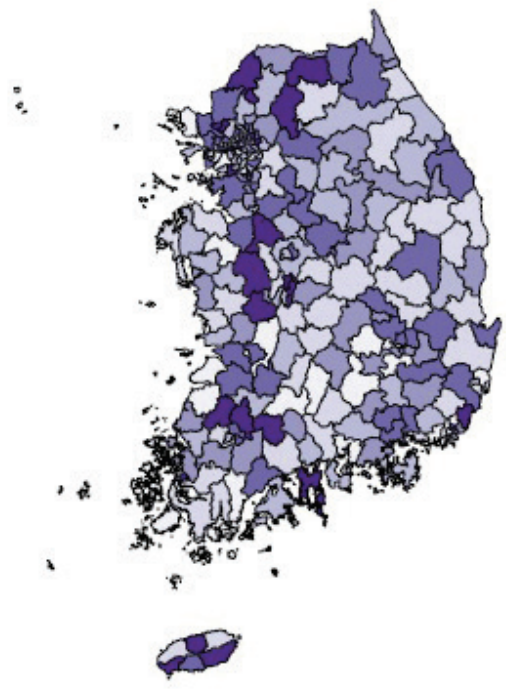

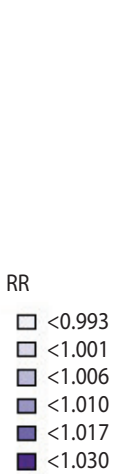

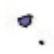

Effect of passive smoking (in work) on stroke

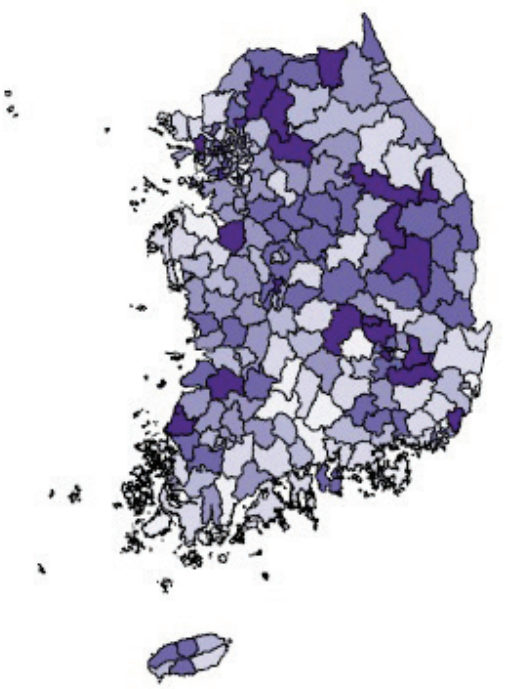

RR

$\square<1.001$

$\square<1.010$

$\square<1.015$

$\square<1.020$

$\square<1.029$

B

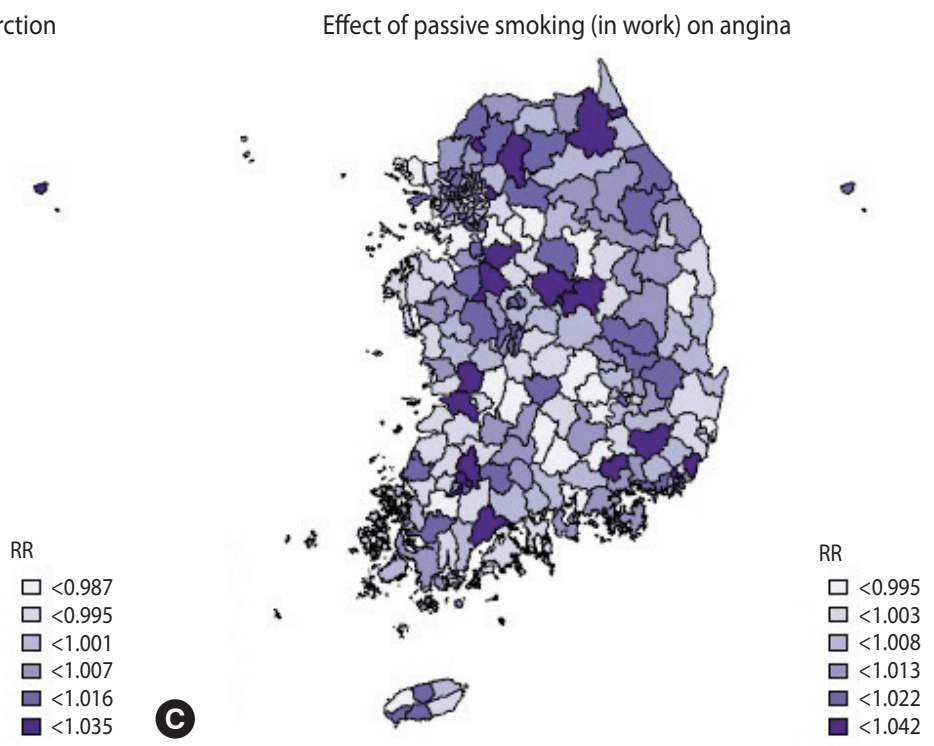

Figure 3. Geographical distribution of relative risks (RR). The associations between 4 cardiovascular diseases (A) hypertension over 30 years, (B) stoke over 50 years, (C) myocardial infarction over 40 years, and (D) angina over 40 years and passive smoking at work.

\section{(RR, 0.998 to 1.013 ).}

In addition to the national-level analysis, this study also analyzed the effects of smoking regionally in 253 regions, based on the assumption that specific regional features (geographical location, environment, income, population matrix) may have varying effects on the prevalence of CVD and may alter the effects of smoking on CVD. Our findings showed that RR of smoking varied across regions, suggesting that the effects of smoking on CVD varied across regions. The effects of smoking and passive smoking on all CVD were high in urban-industrial regions.

Nicotine, the primary ingredient of tobacco, is a sympathetic stimulant that acts on the central and peripheral nervous systems to stimulate the release of catecholamine and other neurotransmitters. It leads to cardiovascular consequences, such as elevating the heart rate, blood pressure, and cardiac output. Furthermore, it leads to a rise in low-density lipoprotein and decrease in high-density lipoprotein by mobilizing free fatty acids, thereby intensifying vasoconstriction and accelerating the progression of blood epithelial cell injury and atherosclerosis [1]. Carbon monoxide that is inhaled through smoking and passive smoking binds with hemoglobin to induce hypoxia, which increases the number of red blood cells and subsequently, blood viscosity thereby, having a direct impact on thrombosis and atherosclerosis [22]. Through these actions, smoking not only causes coronary artery diseases but also 
induces structural damage to arterial walls, and has also been associated with ischemic stroke caused by atherosclerosis and nontraumatic subarachnoid hemorrhage caused by formation and rupture of aneurysm [23].

This study presents data that support these biological causes. Although smoking indices were not statistically significantly associated with myocardial infarction and angina, the RR of smoking was above 1 for all CVDs at the national level (RR, 1.004 to 1.010). These results are in line with those reported by US and Norwegian studies on the relationship between smoking and heart diseases $[3,4]$. According to a foreign 20-year retrospective study, the greater the degree of exposure to passive smoking (cotinine concentration) was, the greater the risk for coronary artery disease and stroke [24]. Another study involving experimental and control groups revealed that the risk for myocardial infarction increases by $68 \%$ among passive smokers [25]. Furthermore, a meta-analysis of studies in 6 countries found that the RR for CVDs was between 1.2 and 1.3 [26]. In one study, passive smoking was found to be more of a health-hazard than direct smoking because smoke from the tip of a cigarette is more harmful than filtered smoke [27]. Our study also found similar results, and our results showed that the $\mathrm{RR}$ of passive smoking at home on angina $(R R, 1.016)$ was higher than that of direct smoking $(R R, 1.007)$.

Nevertheless, this study has a few limitations. First, this study merely analyzed associations and not the causal relationships between smoking indices and CVD. It is difficult to consider the temporal relations of smoking indices and CVD with KCHS data because this was a cross-sectional study [18]. In addition, this study did not consider risk factors at the individual level, so the results should be interpreted as a regional association and not as causal relations. Second, we were able to predict regions that were vulnerable to smoking and passive smoking but could not identify the biological and epidemiological causes of their vulnerability. More specifically, this study was able to verify that people with CVD in urban regions (including industrial regions) are relatively more vulnerable to smoking and passive smoking, but we could not shed light on the fundamental hypothesis and cause after adjusting for gender and age. We expect follow-up studies to evaluate the cause and to explain these results via diverse investigations and advanced analytical methods. Finally, this study did not consider social indicators. CVD may be influenced by social factors, such as income level and environment, but this study could not take these into considerations due to a lack of appropriate data. However, we partially compensated for this by examining potential regional features through performing a longitudinal analysis using a random effect model $[28,29]$.

Despite a few limitations, this study offers several benefits. First, the large sample size of more than 1.5 million subjects increased the accuracy of our analysis in identifying the associations between CVD and smoking indices. Particularly, most of the 4 CVD studied were strongly associated with the smoking indices, with stroke having the greatest association with smoking and passive smoking ( $R R, 1.013$ to 1.060$)$. Second, by using an advanced statistical method, we were able to predict RRs not only at the national but also regional levels. The INLA method [20] predicts post-distributions as does the Markov Chain Monte Carlo method that is widely used in Bayesian statistical analysis, but the INLA is quicker and is easier for expanding distributions [30]. This study is valuable in that it simultaneously analyzed national and regional level risks by performing a Bayesian hierarchical analysis, considering regional correlations with the INLA.

Furthermore, the findings of this study can be used as the grounds for public healthcare policies that limit smoking and passive smoking nationwide to promote people's health. Particularly, they will contribute to devising region-specific healthcare policies for regions populated by groups of people who may be vulnerable to CVD. In other words, there is a need to implement more active measures to limit smoking and to respond to the problems of indoor passive smoking in regions with high populations of people vulnerable to CVD, such as the elderly and financially unstable groups.

\section{ACKNOWLEDGEMENTS}

This work was supported by the Korea Ministry of Environment as Climate Change Correspondence Program (grant no. 20140013 10007).

\section{CONFLICT OF INTEREST}

The authors have no conflicts of interest to declare for this study.

\section{SUPPLEMENTARY MATERIAL}

Supplementary material (Korean version) is available at http:// www.e-epih.org/.

\section{ORCID}

Whanhee Lee: http://orcid.org/0000-0001-5723-9061; Sung-Hee Hwang: http://orcid.org/0000-0002-0017-2238; Hayoung Choi: http://orcid.org/0000-0002-7765-4542; Ho Kim: http://orcid.org/ 0000-0001-7472-3752

\section{REFERENCES}

1. Bullen C. Impact of tobacco smoking and smoking cessation on cardiovascular risk and disease. Expert Rev Cardiovasc Ther 2008; 6:883-895.

2. Centers for Disease Control and Prevention (CDC). Smoking-attributable mortality, years of potential life lost, and productivity losses--United States, 2000-2004. MMWR Morb Mortal Wkly Rep 2008;57:1226-1228.

3. Kuller LH, Ockene JK, Meilahn E, Wentworth DN, Svendsen KH, Neaton JD. Cigarette smoking and mortality. MRFIT Research Group. Prev Med 1991;20:638-654. 
4. Håheim LL, Holme I, Hjermann I, Leren P. Risk factors of stroke incidence and mortality. A 12-year follow-up of the Oslo Study. Stroke 1993;24:1484-1489.

5. Kannel WB, D’Agostino RB, Belanger AJ. Fibrinogen, cigarette smoking, and risk of cardiovascular disease: insights from the Framingham Study. Am Heart J 1987;113:1006-1010.

6. Ockene IS, Miller NH. Cigarette smoking, cardiovascular disease, and stroke: a statement for healthcare professionals from the American Heart Association. American Heart Association Task Force on Risk Reduction. Circulation 1997;96:3243-3247.

7. International Agency for Research on Cancer (IARC). IARC monographs on the evaluation of carcinogenic risks to humans; 2004 [cited 2017 Jun 20]. Available from: http://monographs.iarc.fr/ ENG/Monographs/vol106/index.php.

8. Glantz SA, Parmley WW. Passive smoking and heart disease. Epidemiology, physiology, and biochemistry. Circulation 1991;83:112 .

9. Law MR, Morris JK, Wald NJ. Environmental tobacco smoke exposure and ischaemic heart disease: an evaluation of the evidence. BMJ 1997;315:973-980.

10. Thun M, Henley J, Apicella L. Epidemiologic studies of fatal and nonfatal cardiovascular disease and ETS exposure from spousal smoking. Environ Health Perspect 1999;107 Suppl 6:841-846

11. Lee EH, Park SK, Ko KP, Cho IS, Chang SH, Shin HR, et al. Cigarette smoking and mortality in the Korean Multi-center Cancer Cohort (KMCC) study. J Prev Med Public Health 2010;43:151158 (Korean),

12. Meng KH. Smoking-attributable mortality among Korean adults. Korean J Epidemiol 1988;10:138-145 (Korean).

13. Jee SH, Lee JK, Kim IS. Smoking-attributable mortality among Korean adults: 1981-2003. Korean J Epidemiol 2006;28:92-99 (Korean).

14. Jung KJ, Yun YD, Baek SJ, Jee SH, Kim IS. Smoking-attributable mortality among Korean adults, 2012. J Korea Soc Health Inform Stat 2013;38:36-48 (Korean).

15. Korean Statistical Information Service. Current smoking rate 20082016 [cited 2017 Jul 20]. Available from: http://kosis.kr/statHtml/ statHtml.do? orgId = 117\&tblId = DT_H_SM\&conn_path = I2\& language $=$ en .

16. Kim J, Son M. National health insurance statistical yearbook. Seoul: Health Insurance Review and Assessment Service and National
Health Insurance Service; 2014, p. 62-67 (Korean).

17. Kim YT, Choi BY, Lee KO, Kim H, Chun JH, Kim SY, et al. Overview of Korean Community Health Survey. J Korean Med Assoc 2012;55:74-83 (Korean).

18. Lee WH, Choo JY, Son JY, Kim H. Association between long-term exposure to air pollutants and prevalence of cardiovascular disease in 108 South Korean communities in 2008-2010: a cross-sectional study. Sci Total Environ 2016;565:271-278.

19. Besag J, York J, Mollié A. Bayesian image restoration, with two applications in spatial statistics. Ann Inst Stat Math 1991;43:1-20.

20. Rue H, Martino S, Chopin N. Approximate Bayesian inference for latent Gaussian models by using integrated nested Laplace approximations. J R Stat Soc Series B Stat Methodol 2009;71:319392.

21. Martino S, Rue H. Implementing approximate Bayesian inference using integrated nested Laplace approximation: a manual for the INLA program; 2008 [cited 2017 Jun 20]. Available from: http:// www.bias-project.org.uk/GMRFCourse/inla-program.pdf.

22. Ambrose JA, Barua RS. The pathophysiology of cigarette smoking and cardiovascular disease: an update. J Am Coll Cardiol 2004; 43:1731-1737.

23. Kurth T, Kase CS, Berger K, Gaziano JM, Cook NR, Buring JE. Smoking and risk of hemorrhagic stroke in women. Stroke 2003; 34:2792-2795.

24. Whincup PH, Gilg JA, Emberson JR, Jarvis MJ, Feyerabend C, Bryant A, et al. Passive smoking and risk of coronary heart disease and stroke: prospective study with cotinine measurement. BMJ 2004;329:200-205.

25. Wells AJ. Heart disease from passive smoking in the workplace. J Am Coll Cardiol 1998;31:1-9.

26. He J, Vupputuri S, Allen K, Prerost MR, Hughes J, Whelton PK. Passive smoking and the risk of coronary heart disease--a metaanalysis of epidemiologic studies. N Engl J Med 1999;340:920-926.

27. Dobson R. Smoke from cigarette tip is more toxic than main inhaled smoke. BMJ 2005;331:1425.

28. Laird NM, Ware JH. Random-effects models for longitudinal data. Biometrics 1982;38:963-974.

29. Liang KY, Zeger SL. Longitudinal data analysis using generalized linear models. Biometrika 1986;73:13-22.

30. Blangiardo M, Cameletti M. Spatial and Spatio-temporal Bayesian models with R-INLA. New York: John Wiley \& Sons; 2015. 
Appendix 1. Statistical analysis formulation

\section{Gamma distribution}

$$
\begin{gathered}
\mathrm{f}\left(y_{i}\right)=\frac{1}{\Gamma(v)}\left(\frac{v y}{\mu}\right)^{v} \exp \left(\frac{-v y}{\mu}\right), y \geq 0, \mu>0, v>0 \\
Y_{i} \sim \Gamma(\mu, v) \\
\log (v) \sim \log \operatorname{Gamma}(1,0.01)
\end{gathered}
$$

where $Y_{i}$ is a observed values with $i=1,2, \ldots \mathrm{N}$. We assumed Gamma distribution as a distribution of $Y_{i}$ with parameter $\mu$ and $v$. And we set the prior distribution of $\log (v)$ as $\log G a m m a$ distribution with parameter 1 , and 0.01 each.

\section{Integrated nested Laplace approximation (INLA)}

$$
\begin{gathered}
\mathrm{p}(\mathrm{y} \mid \boldsymbol{\beta}, \boldsymbol{\Psi})=\prod_{i=1}^{n} p\left(y_{i} \mid \beta_{i}, \boldsymbol{\psi}\right) \\
\mathrm{p}(\boldsymbol{\beta} \mid \boldsymbol{\Psi})=(2 \pi)^{-\frac{n}{2}}|\mathrm{Q}(\boldsymbol{\Psi})|^{\frac{1}{2}} \exp \left(-\frac{1}{2} \boldsymbol{\beta}^{\prime} \mathrm{Q}(\boldsymbol{\Psi}) \boldsymbol{\beta}\right)
\end{gathered}
$$

The INLA algorithm, proposed by Rue et al. [1] and Martino \& Rue [2] is a deterministic algorithm for Bayesian inference rather than simulation based, MCMC (Markov Chain Monte Carlo). $\beta$ is a set of regression coefficient parameter and Q $(\psi)$ is a sparse precision matrix known as Gaussian Markov random field (GMRF).

\section{Regression model}

$$
\begin{gathered}
\log \left(\mu_{i j}\right) \sim\left(\beta_{0}+b_{0 j}+b_{2 j}\right)+\left(\beta_{1}+b_{1 j}\right) X_{i j}+\boldsymbol{\beta}_{-0,1} Z \\
b_{0 j} \sim \operatorname{Normal}\left(0, \sigma_{b 0}^{2}\right), b_{1 j} \sim \operatorname{Normal}\left(0, \sigma_{b 1}^{2}\right) \\
1 / \sigma_{v 0}^{2} \sim \log \operatorname{Gamma}(1,0.00005), 1 / \sigma_{v 1}^{2} \sim \log \operatorname{Gamma}(1,0.00005)
\end{gathered}
$$

$\beta_{0}$ is an intercept of regression model and $X$ is an interesting variable (smoking, indirect smoking indices, each). Bayesian hierarchical model is used with hyper parameters; $\psi=\left(\sigma_{v 0}^{2}, \sigma_{v 1}^{2}\right.$, etc $)$.

\section{Besag-York-Mollie (BYM) model}

$$
\begin{gathered}
b_{2 j}=u_{j}+v_{j} \\
u_{j \mid} u_{-j} \sim \operatorname{Normal}\left(\frac{1}{N_{i}} \sum_{k} a_{j k} u_{k}, s_{j}^{2}\right), v_{j=} \operatorname{Normal}\left(0, \sigma_{v}^{2}\right)
\end{gathered}
$$

Considering $\mathrm{N}$ areas, each characterized by a set of neighbors $N_{j}$. And $a_{j k}$ is 1 if areas $\mathrm{j}$ and $\mathrm{k}$ are neighbors and 0 otherwise. $s_{j}^{2}=\sigma_{u}^{2} / N_{j}$ is the variance for the same area. $v_{j}$ is the area-specific effect modeled as exchangeable.

\section{References}

1. Rue H, Martino S, Chopin N. Approximate Bayesian inference for latent Gaussian models by using integrated nested Laplace approximations. J R Stat Soc Series B Stat Methodol 2009;71:319-392.

2. Martino S, Rue H. Implementing approximate Bayesian inference using integrated nested Laplace approximation: a manual for the INLA program; 2008 [cited 2017 Jun 20]. Available from: http://www.bias-project.org.uk/GMRFCourse/inla-program.pdf. 